\title{
Physiological Ecology of Leucothrix mucor
}

\author{
By M. T. KELLY AND T. D. BROCK \\ Department of Microbiology, Indiana University, Bloomington, Indiana 4740I, U.S.A.
}

\author{
(Accepted for publication 20 August 1969)
}

\begin{abstract}
SUMMARY
Temperature, salinity and $\mathrm{pH}$ optima of the marine bacterium Leucothrix mucor were determined directly in nature by use of tritiated thymidine autoradiography and compared with the same characteristics of laboratory cultures. Field studies were done in Puget Sound, Washington, U.S.A., and Loch Ewe, Scotland. The temperature optima of cultures isolated from various sea-coast areas around the world were $28^{\circ}$, irrespective of the temperature of the habitat from which the culture was derived. In contrast, the temperature optima in the natural environment were significantly lower, ranging from $6.5^{\circ}$ to $25^{\circ}$, depending on the habitat studied. Attempts to obtain physiological adaptation of laboratory cultures to low temperature failed. The results emphasize the danger of inferring the response to temperature of natural populations from the characteristics of laboratory cultures. In contrast, responses to salinity and $\mathrm{pH}$ optima in natural environments were the same as those of laboratory cultures.
\end{abstract}

\section{INTRODUCTION}

The development of an autoradiographic technique using tritiated thymidine for measuring growth rates of the marine bacterium Leucothrix mucor directly in its natural environment (Brock, 1967) opened up the possibility of studying the physiological ecology of natural populations of this organism. In previous work in marine bacteriology, the behaviour of natural populations was inferred from the characteristics of laboratory cultures. Because of the widespread ability of bacteria to adapt to changing environments, it is possible that the characteristics of laboratory cultures do not reflect those of the same organism in nature. We were especially interested in studying the temperature optima of $L$. mucor directly in the sea because this organism was generally found in cool temperate waters, but the temperature optima of all pure cultures isolated were considerably higher than the temperatures of the habitats in which the organism lives.

The present paper reports studies carried out in two temperate sea-coast regions which are geographically distant from each other but which are ecologically similar, namely the west coast of Scotland and Puget Sound in the region of Friday Harbor, Washington, U.S.A. Leucothrix mucor is a bacterial epiphyte of seaweeds and is especially common on filamentous red and green algae living in habitats where water flow and aeration are good due to extensive wave action or tidal current (Brock, I966). In such habitats, L. mucor is often virtually the only epiphyte present, and because of its large size and distinctive morphology it can easily be recognized microscopically. The plan of the experiments was to remove algal fronds containing $L$. mucor from a variety of habitats of known characteristics, place them at a number of different 
temperatures, salinities and $\mathrm{pH}$ values and without preadaptation measure the growth rates by tritiated thymidine autoradiography. At the same time, a number of pure cultures of $L$. mucor were isolated and the temperature, salinity and $\mathrm{pH}$ optima of these cultures determined in the laboratory. The results showed that the temperature optima of the natural material varies markedly but was usually lower than the optima of pure cultures. The manner in which ecological adaptation to low temperatures might occur is discussed, especially in relation to the absence of similar adaptation to low temperatures by laboratory cultures. On the other hand, salinity and $\mathrm{pH}$ optima determined in the natural environment are quite similar to those of laboratory cultures.

\section{METHODS}

Habitats. Most of the experiments were done in the waters around San Juan Island, Puget Sound, Washington, U.S.A. The experiments were done in the summer of 1967, and the water temperatures of the habitats selected remained relatively constant throughout this time (except as noted). The area is characterized by generally cold waters ( 12 to $13^{\circ}$ ) and rocky shorelines with abundant algal growth and ample wave action. There are however shallow-water areas where the water, warmed by sunlight, reaches temperatures as high as 20 to $22^{\circ}$. There are other areas where a sandy shoreline with moderate wave action exists. Therefore the area where these studies were done presented a wide variety of habitats, and the temperature adaptation of Leucothrix mucor could be studied in several different types of environment. The habitats and their characteristics are described below, and for clarity the habitats will be referred to henceforth by their designated letters. Habitat A: South Beach; temperature, $12^{\circ}$; tidal range, low intertidal; terrain, pebble beach with large boulders; aeration, strong wave action; algal substrate, a branched rhodophyte (Pterosiphonia and Polysiphonia spp.); habitat rarely exposed to drying. Habitat B: location, Eagle Cove; temperature, $12.5^{\circ}$; tidal range, low intertidal; terrain, sandy beach with large boulders; aeration, moderate wave action; algal substrate, branched rhodophyte (Pterosiphonia and Polysiphonia spp.); habitat rarely exposed to drying. Habitat C: location, Argyle Lagoon Channel; temperature, 13 to $20^{\circ}$; tidal conditions, tidal creek connecting open water $\left(13^{\circ}\right.$ water) with a lagoon $\left(20^{\circ}\right.$ water) (at high tide water flows into the lagoon while at low tide water flows out of the lagoon, and therefore the temperature fluctuates between $13^{\circ}$ and $20^{\circ}$ due to changes in the direction of flow of the tidal creek); terrain, pebbles and rocks up to $\mathrm{I} 2$ in. diameter; aeration, moderate due to flowing water; algal substrate, branched rhodophyte (Pterosiphonia and Polysiphonia spp.). Habitat D: location, shoreline north of Friday Harbor, Washington, U.S.A.; temperature, $13^{\circ}$; tidal range, middle intertidal; terrain, large boulders on shelf rock; aeration, moderate wave action; algal substrate, unbranched rhodophyte (Bangia fuscopurpurea); habitat sometimes exposed to drying at low tide. Habitat E: location, shoreline north of Friday Harbor, Washington, U.S.A.; temperature, $15^{\circ}$; tidal range, high intertidal; terrain, flat shelf rock; aeration, moderate wave action; algal substrate, unbranched rhodophyte (Bangia fuscopurpurea); habitat frequently exposed to drying at low tide. Habitat F: location, South Beach; temperature, $13^{\circ}$; tidal range, middle intertidal; terrain, pebble beach with large boulders; aeration, moderate wave action; algal substrate, unbranched chlorophyte; habitat sometimes exposed to drying at low tide. 
One series of experiments was done at Firemore, Loch Ewe, Scotland, an area of this large sea loch which is relatively exposed to the open ocean. The oceanographic characteristics of this area were presented by Steele \& Baird (1968). The present work was done with material collected at low tide from a rocky headland adjacent to the sandy bay studied by Steele \& Baird (1968), and the incubations were done within one half-hour of collection at a small field laboratory made available at the site by the Marine Laboratory, Department of Agriculture and Fisheries, Aberdeen, Scotland. The samples were collected in locations which were submerged even at low tide. The experiments were done in April 1966 when the water temperature was $6.5^{\circ}$. The temperature of this same habitat in midsummer rarely exceeds $14^{\circ}$.

Experimental techniques. The relative rate of incorporation of tritiated thymidine at various temperatures, salinities and $\mathrm{pH}$ values was used to determine the optima for these factors for DNA synthesis in Leucothrix mucor taken directly from nature. The assumptions and justification for the use of tritiated thymidine incorporation to measure the growth rate of $L$. mucor in nature were presented by Brock (1967).

In a typical temperature adaptation experiment, samples of algae known to contain Leucothrix mucor were taken from the sea and placed in large plastic bags. The samples were then returned to the laboratory within one hour, and were kept as close to the environmental temperature as possible. Small samples of algal fronds were transferred to $5 \mathrm{ml}$. screw-capped vials containing $0.9 \mathrm{ml}$. of seawater from the area of sample collection. The vials were then equilibrated in water baths and incubators at six or seven temperatures for $15 \mathrm{~min}$. Tritiated thymidine was added by injecting $0 . \mathrm{I} \mathrm{ml}$. of a $10 \mu \mathrm{c} . / \mathrm{ml}$. stock solution without removing the vials from the incubators. After $\mathrm{I} \mathrm{hr}, \mathrm{O} \cdot \mathrm{I} \mathrm{ml}$. of formalin was injected into each vial to terminate the experiment. For studies on the effect of salinity and $\mathrm{pH}$ value, a temperature of $25^{\circ}$ was used. The experiments were done using samples taken from Habitat $\mathrm{B}$. $\mathrm{pH}$ Values ranging from 2.4 to 10.7 were obtained by addition of concentrated $\mathrm{HCl}$ or $\mathrm{NaOH}$ to natural seawater. A range of salinities was obtained by use of seawater concentrated by evaporation.

A detailed description of the preparation of autoradiograms has been presented by Brock \& Brock (1968), and the procedure will be described only briefly here. An algal frond from each incubation vial was placed on a microscope slide which had been coated with Ullrich's adhesive. The frond was spread out and allowed to dry overnight at $40^{\circ}$. The slides were then washed five times for I min. in distilled water and dried. They were then coated with emulsion by dipping into Eastman Kodak NBT-2 nuclear track emulsion (diluted $\mathrm{I} / 2.5$ ) and dried. The slides were left in the dark for 5 days and then developed. The number of labelled and unlabelled cells was determined using a $40 \times($ N.A. 0.75$)$ phase-contrast water-immersion lens on a Zeiss microscope equipped with $12.5 \times$ eyepieces.

In counting the autoradiograms, ten filaments were chosen at random and the number of labelled and unlabelled cells determined. A minimum of 250 cells was counted for each autoradiogram, and the results are expressed as per cent labelled cells.

Laboratory studies. The strains of Leucothrix mucor used in these studies were isolated from various areas around the world, and their sources were given by Brock \& Mandel (1966) and by Kelly (1969). One strain (no. 19) isolated from warmer waters in the Florida Keys had temperature relations different from the others (Kelly \& Brock, 1969). Temperature optima of laboratory cultures were determined 
roughly by estimating the amount of growth of liquid cultures incubated at different temperatures for a standard period of time. More detailed temperature optima were determined for some strains either by measuring the rate of increase of turbidity and protein content in shaken liquid cultures or by measuring the rate of increase of diameter of colonies growing on agar plates incubated at various temperatures. The latter procedure permitted measurement of growth rates on a number of strains simultaneously. The agar plates were inoculated with appropriate dilutions of suspensions of gonidia (obtained by the filtration method of Harold \& Stanier, 1955) so that about 100 colonies developed on each plate. The colony diameters were measured daily or less frequently depending on growth rate and, from these measurements, the relative growth rates at various temperatures were estimated. The defined medium of Brock (I966) was used for these studies, with $\mathrm{I} \cdot 0 \%(\mathrm{w} / \mathrm{v})$ or $0 . \mathrm{I} \%(\mathrm{w} / \mathrm{v})$ monosodium glutamate as sole source of carbon, nitrogen and energy.

To determine temperature optima for laboratory cultures previously grown for at least $\mathrm{I} 5$ generations at $2^{\circ}, 10^{\circ}, 25^{\circ}$ or $30^{\circ}, 5^{\circ} \mathrm{ml}$. samples of early exponential-phase cultures were removed and incubated with aeration at temperatures ranging from $0^{\circ}$ to $35^{\circ}$ for $5 \mathrm{~min}$. to allow equilibration. Tritiated thymidine $(\mathrm{I} \cdot 0 \mu \mathrm{c} . / \mathrm{ml}$.) was then added, and the incorporation was terminated by addition of formalin (final concentration $4 \%$ ) after $\mathrm{I} \mathrm{hr}$. This technique made it possible to determine whether there was any transitory adaptation to various temperatures. In a preliminary experiment, it was shown that incorporation of tritiated thymidine as followed by autoradiography closely paralleled that measured by liquid scintillation counting (Fig. I). Therefore, the samples were supplemented with cold $5 \%$ trichloroacetic acid, filtered, and the precipitate washed and counted in a Packard Tri-Carb liquid scintillation system using a toluene-PPO-POPOP scintillation liquid. The strains were grown at various $\mathrm{pH}$ values and salinities in a synthetic seawater-salts medium supplemented with $0.1 \%$ (w/v) mono-sodium glutamate (Brock \& Mandel, 1966), and growth was estimated visually. Although the synthetic seawater had a salinity less than natural seawater, addition of $0.1 \%$ mono-sodium glutamate brought the medium to a salinity the same as natural seawater.

\section{RESULTS}

\section{Response to temperature}

Temperature optima of laboratory cultures. The temperature optima of all strains tested were around 25 to $28^{\circ}$, irrespective of the habitat from which the strain was isolated. The temperature range over which growth occurred was wide, all except three strains growing at 2 to $3^{\circ}$, and most strains growing at 30 to $32^{\circ}$. One strain isolated from warmer waters in the Florida Keys was more stenothermal, and was unable to grow at temperatures below 12 to $13^{\circ}$, although still showing an optimum at about $28^{\circ}$ and a maximum between $32^{\circ}$ and $35^{\circ}$. The characteristics of this strain are reported in greater detail elsewhere (Kelly \& Brock, I969). For strain no. I, generation times have been determined in liquid cultures of $0.1 \%$ glutamate medium, and the doubling time at the optimum temperature of $28^{\circ}$ was about $205 \mathrm{~min}$. At $18^{\circ}$, this strain had a doubling time of $230 \mathrm{~min}$., and at $10^{\circ}$ it was $410 \mathrm{~min}$. In a medium with $0.1 \%$ tryptone $+0.1 \%$ yeast extract instead of glutamate, strain no. I had a generation time of $185 \mathrm{~min}$. at $28^{\circ}$.

Temperature optima in natural environments. Figures 2 to 4 give representative data 
from the extensive series of experiments done at Friday Harbor, Washington, U.S.A. In most experiments, a relatively sharp temperature optimum was found, although the optimum varied from one habitat to another. In Fig. 2 data are presented for two experiments where temperature optima of $13^{\circ}$ were obtained, which in both cases was also the habitat temperature. Note that, although the temperature optima were the same, the growth rate (as indicated by the percentage of labelled cells) was more

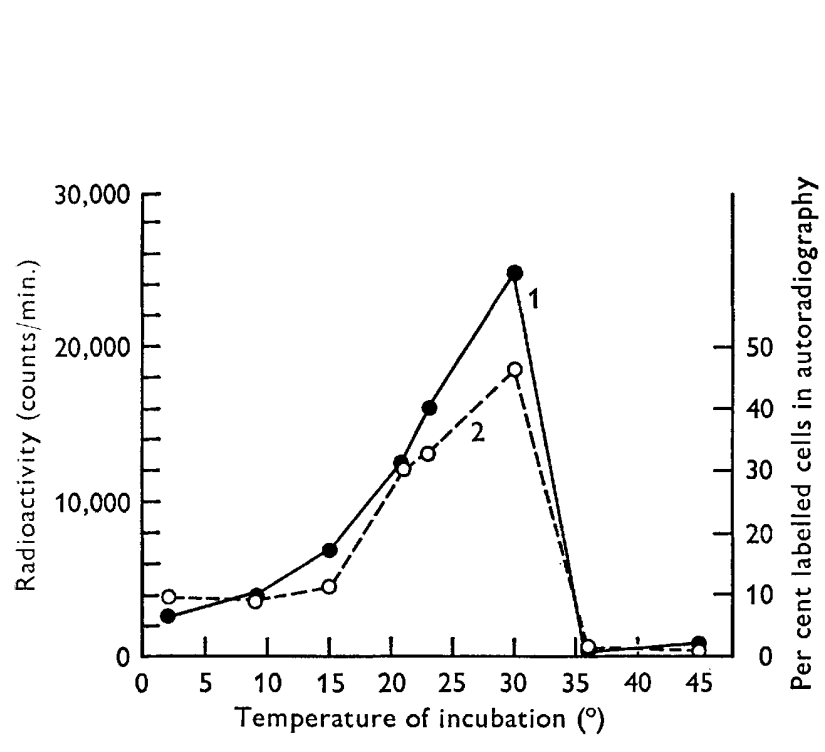

Fig. I

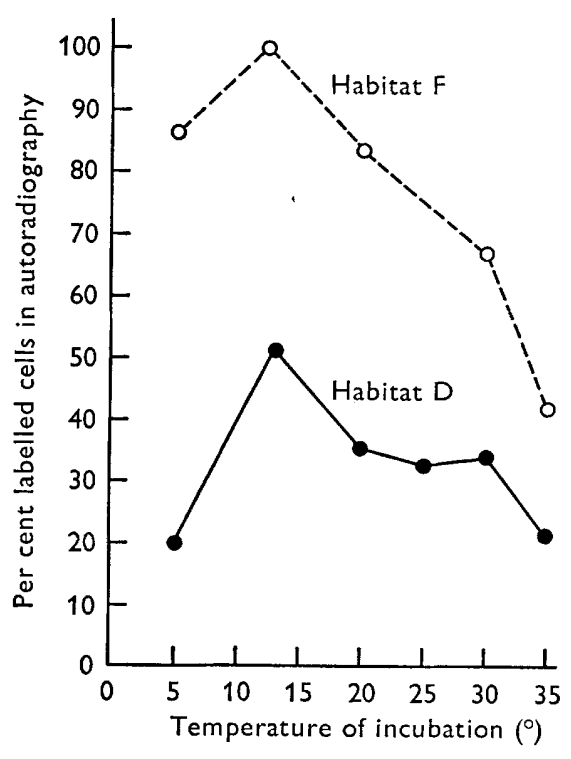

Fig. 2

Fig. I. Radioactivity of Leucothrix mucor as measured by liquid scintillation counting and autoradiography. Samples of a suspension of organisms which had been cultured at $10^{\circ}$ were incubated at various temperatures in a solution containing $\mathrm{I} \mu \mathrm{C}$. tritiated thymidine per $\mathrm{ml}$. for $\mathrm{I} \mathrm{hr}$ and then assayed. Curve I shows results for scintillation counting; curve 2 for autoradiography (per cent labelled cells per $6 \mathrm{~min}$. incubation).

Fig. 2. Temperature optima for growth of natural populations of Leucothrix mucor from habitats $\mathrm{D}$ and $\mathrm{F}$ as measured by autoradiography. Temperatures of habitats: $\mathrm{D}, \mathrm{I}^{\circ}$; $\mathrm{F}, 13^{\circ}$.

rapid at one of these habitats than at the other. In contrast, Fig. 3 presents data from two separate experiments at a habitat where the temperature optimum was $25^{\circ}$. Note also that the optimum in Fig. 3 is much sharper than that of Fig. 2. The seawater temperature at the habitat where the experiments shown in Fig. 3 were done was only slightly higher than those of Fig. 2, but a major difference was that the habitat of the experiments in Fig. 3 was in the high intertidal range and the algae were frequently exposed to drying at low tide. Under such conditions, the seaweeds became considerably warmed by sunlight and hence the $L$. mucor populations were exposed to higher temperatures.

Figure 4 presents results of two experiments done in the tidal creek connecting Argyle Lagoon with the sea. As noted in Materials and Methods, the temperature of this creek fluctuated through the tidal cycle from $13^{\circ}$ to $20^{\circ}$. In one experiment, two distinct temperature optima at $10^{\circ}$ and $25^{\circ}$ were found, whereas in the second experiment there was an optimum at $25^{\circ}$ and a shoulder at $10^{\circ}$. 
Five experiments were done with samples from habitats $\mathrm{A}$ and $\mathrm{B}$ where the water temperature was about $12^{\circ}$, and the algae were rarely exposed to drying. All these experiments showed optima of about $20^{\circ}$. The data for the one experiment done at Loch Ewe, Scotland, are presented in Fig. 5. The maximum growth rate was found at the lowest temperature used, $6.5^{\circ}$, which was the temperature of the habitat. However, the growth rate was not much slower at temperatures of $13.5^{\circ}$ and $18^{\circ}$, suggesting that at this habitat there was a fairly broad temperature optimum. The experiment at Loch Ewe was done in April, and the seaweeds even at low tide would have been

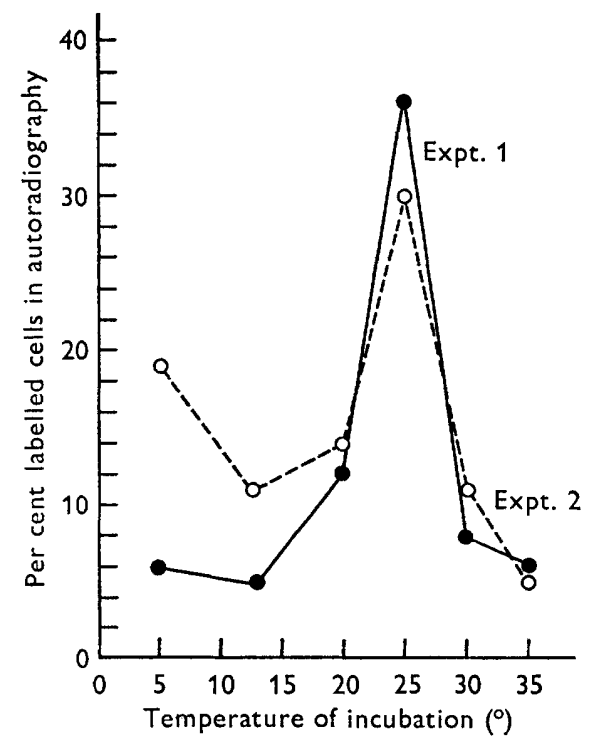

Fig. 3

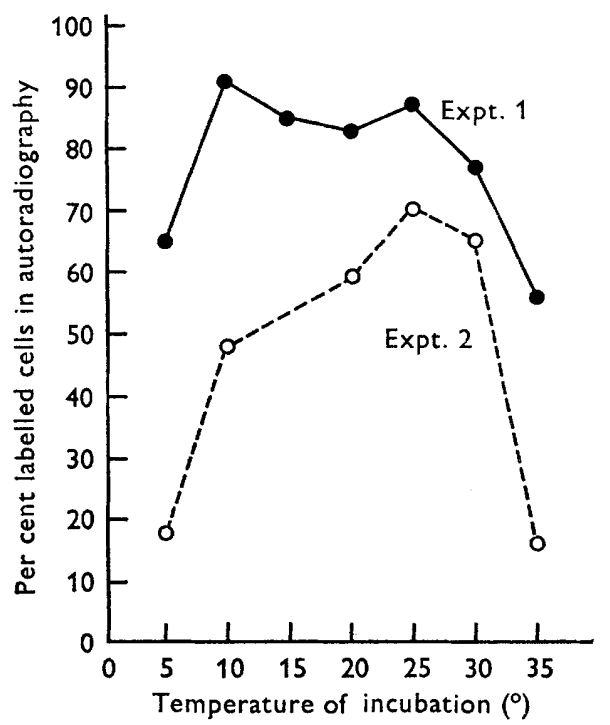

Fig. 4

Fig. 3. Temperature optimum for growth of natural populations of Leucothrix mucor from habitat $\mathrm{E}$ as measured by autoradiography. Experiments $\mathrm{I}$ and 2 were done with different samples of algae. Temperature of habitat: $15^{\circ}$ but warming during drying at low tide.

Fig. 4. Temperature optimum for growth of natural populations of Leucothrix mucor from habitat $C$ as measured by autoradiography. Experiment I was done on 8 July 1967 and

Expt. 2 done on 10 August 1967. Temperature of habitat: variable from $13^{\circ}$ to $20^{\circ}$.

subjected to only fairly low temperatures because of the cool cloudy weather over the previous winter months. Another experiment was done at Loch Ewe in late July, 1967, but unfortunately the $L$. mucor populations on the algae were too low.

Temperature adaptation in laboratory cultures. Because many of the temperature optima found in natural populations were considerably lower than those of laboratory cultures, it was considered of interest to see if $L$. mucor cultures would show short-term adaptation to low temperatures. Consequently a series of experiments was done in which $L$. mucor was grown for at least 15 generations at low temperatures, and the immediate response of these cultures to warming was studied. To make these studies analogous to those done in nature, and to make possible the measurement of only transient adaptation to low temperature, the rate of incorporation of tritiated thymidine was measured by liquid scintillation counting. In these studies the samples were incubated at the various temperatures for only $5 \mathrm{~min}$. before tritiated thymidine was added. The data from one experiment are summarized in Fig. 6. 
It can be seen that the optimum temperature for tritiated thymidine incorporation was about $26^{\circ}$ regardless of whether the cultures were grown at $2,10,25$ or $30^{\circ}$. In three other experiments in which cultures were grown at $10^{\circ}$ and in two in which cultures were grown at $2^{\circ}$, optima of 25 to $30^{\circ}$ were found. Thus, there was no adaptation to growth at low temperatures under the conditions used in the laboratory.

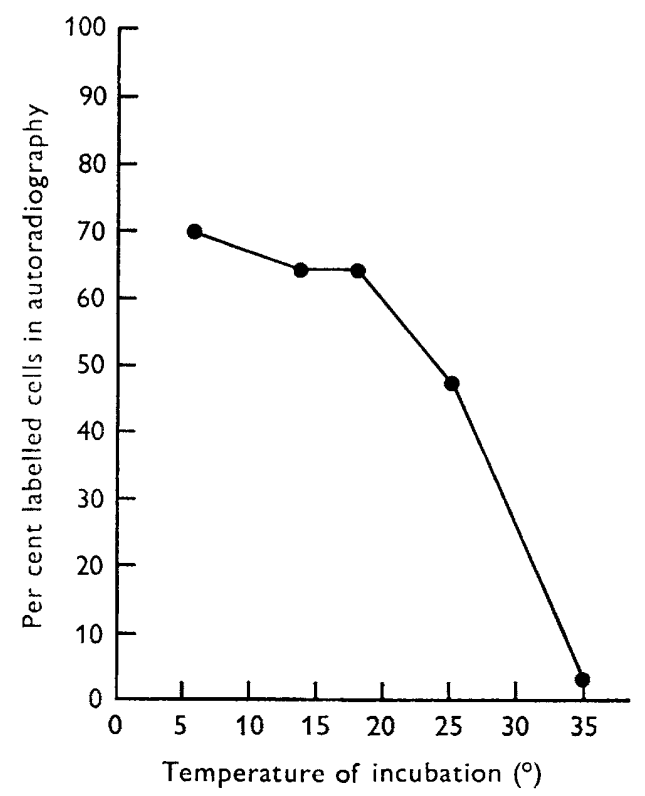

Fig. 5

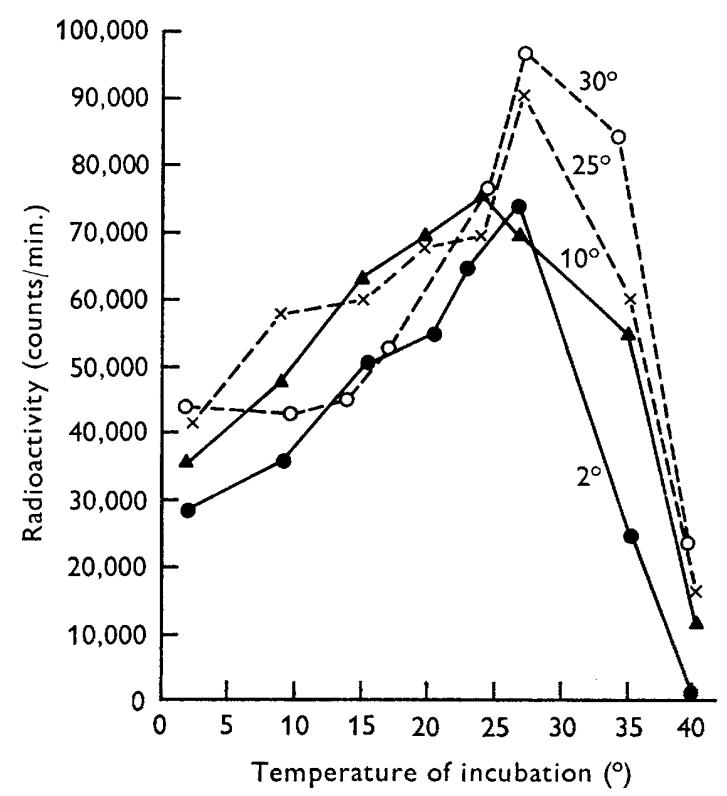

Fig. 6

Fig. 5. Effect of temperature on incorporation of tritiated thymidine as measured by autoradiography for populations of Leucothrix mucor from Loch Ewe, Scotland. Temperature of habitat: $6 \cdot 5^{\circ}$.

Fig. 6. Effect of temperature on incorporation of tritiated thymidine as measured by liquid scintillation counting for cultures of Leucothrix mucor strain no. I grown for many generations at the stated temperatures.

\section{Response to $\mathrm{pH}$ value and salinity}

The optimum $\mathrm{pH}$ value for $L$. mucor was 7.6 in culture, and the results of an experiment done under natural conditions are presented in Fig. 7. The optimum pH value of $L$. mucor in the natural environment was between 7.0 and 8.0 and thus corresponds well with the $\mathrm{pH}$ optimum in culture. Results obtained in the salinity studies are presented in Fig. 8. The salinity optimum in culture was found to be around 3I p.p.t. for the 27 strains analysed, and the optimum in the natural environment was almost exactly the same.

\section{DISCUSSION}

The difficulty which existed in attempting to determine the characteristics of an organism in nature from its characteristics in culture was pointed out by ZoBell (1946). He noted that marine bacteria often grew best in the laboratory at temperatures ro to $20^{\circ}$ higher than those of their natural habitats. Similarly, Haight \& Morita (1966) stressed the importance of correlating the results of laboratory and field studies 
involving marine bacteria. They demonstrated that Vibrio marinus differed physiologically when grown under the conditions of the natural environment or under conditions which were optimal for its growth in the laboratory.

In the present study a comparison of the temperature optima of Leucothrix mucor in nature with those obtained in culture emphasized this problem. The temperature optimum of $L$. mucor in culture was found to be about $28^{\circ}$, and all the strains had the same temperature characteristics regardless of their original locations. In contrast,

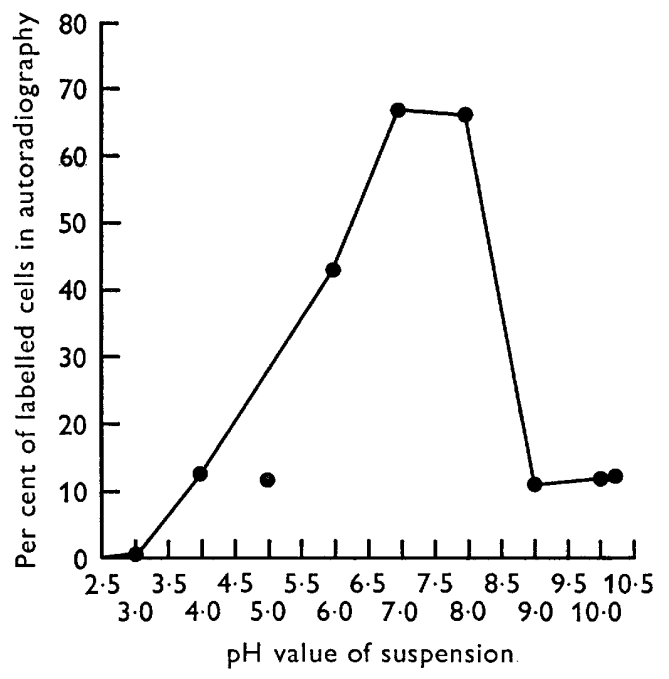

Fig. 7

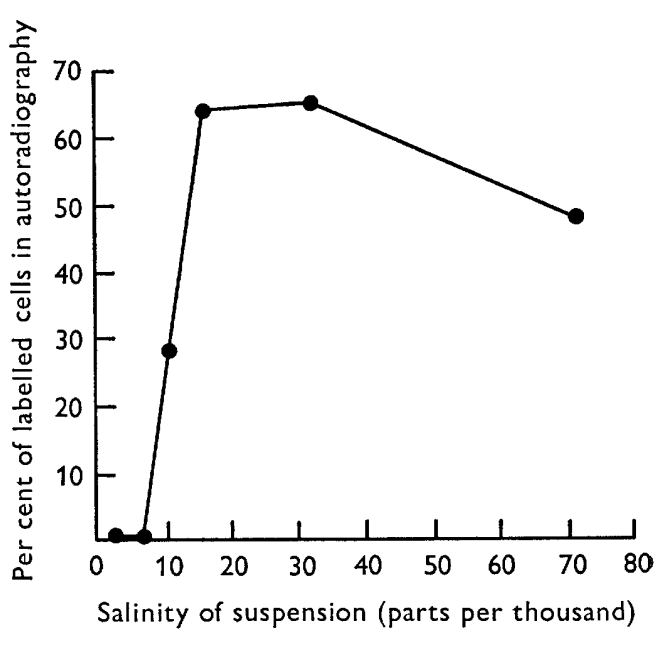

Fig. 8

Fig. 7. Effect of $\mathrm{pH}$ value on the incorporation of tritiated thymidine in natural populations of Leucothrix mucor. An algal sample was removed from the sea and incubated with $\mathrm{I} \cdot \mathrm{O} \mathrm{g}$. of tritiated thymidine $/ \mathrm{ml}$. seawater at various $\mathrm{pH}$ values. The incorporation was measured by autoradiography.

Fig. 8. Effect of salinity on incorporation of tritiated thymidine in natural populations of Leucothrix mucor. An algal sample was removed from the sea and incubated with $\mathbf{I} \cdot 0 \mu \mathrm{g}$. of tritiated thymidine $/ \mathrm{ml}$. sea water at various salinities. The incorporation was measured by autoradiography.

the temperature optima determined for $L$. mucor in its natural environment by autoradiography ranged from 6.5 to $25^{\circ}$ depending on the habitat used, and the optima in all the experiments were lower than the optima in culture. In general, optima in nature were higher in warmer habitats, although this relationship did not always hold.

This discrepancy could be due to a physiological adaptation to the low temperatures of the natural environment. However, efforts to duplicate this adaptation in culture were not successful, suggesting that there may be differences between the conditions in culture and in nature. It must be remembered that $L$. mucor grows in nature as an algal epiphyte and thus probably has a very complex nutritional supply in addition to interactions with other micro-organisms, and such conditions are not duplicated in laboratory cultures.

An alternative explanation for the different optima in culture and in nature could be that since the strains were isolated at temperatures of 20 to $25^{\circ}$, only strains with high temperature optima were obtained. These organisms could be strains which occur in very small numbers in the low-temperature environments but are able to 
grow better than the majority of the organisms at higher temperatures. Evidence that such strains exist has been presented by Sieburth (1967), who was able to show that the temperature optima of the various types of bacteria in Narragansett Bay change as a function of the water temperature. The temperature optima lag two months behind the fluctuations in water temperature suggesting a selection of different temperature strains of each type of organism rather than a physiological adaptation which would require only a few generations to achieve. These strains could arise by random mutation, since it has been shown by Olsen \& Metcalf (1968) that a small number of genetic loci may control the temperature characteristics of an organism. A factor which argued in favour of this interpretation was that only a small percentage of the L. mucor filaments on the plates during isolation actually formed colonies. However, since most of the filaments in each autoradiogram were labelled to the same extent, the number of organisms in the population with optima at 25 to $30^{\circ}$ would have to be quite small.

In contrast to the temperature studies, a good correlation was found between the optima determined in culture and those determined in the natural environment for salinity and $\mathrm{pH}$ value. However, it should be noted that, although the optimum in terms of total salinity was the same in culture and in nature, the concentrations of individual ions were not the same. For example the medium which gave optimal growth had a salinity of $3 \mathrm{I}$ p.p.t. and contained $0.42 \mathrm{M}-\mathrm{Na}^{+}(0.28 \mathrm{M}$ as $\mathrm{NaCl}$ and $0.14 \mathrm{M}$ as monosodium glutamate), $0.027 \mathrm{M}-\mathrm{Mg}^{2+}$, and $0.005 \mathrm{M}-\mathrm{Ca}^{2+}$ while seawater has a salinity of 32 p.p.t. and $0.45 \mathrm{M}-\mathrm{Na}^{+}, 0.05 \mathrm{M}-\mathrm{Mg}^{2+}, 0.0 \mathrm{I} \mathrm{M}-\mathrm{K}^{+}$and $0.0 \mathrm{I} \mathrm{M}-\mathrm{Ca}^{2+}$. It appears therefore that the total salinity may be more important for the growth of $L$. mucor than the concentrations of individual ions.

The effects of individual ions on marine bacteria have been analysed by MacLeod (I965) and by Korngold \& Kushner (1968), but little work has been done on the effects of the over-all salinity on these organisms. Korngold \& Kushner (I968) noted the stabilizing effect of divalent cations on a marine bacterium, and MacLeod emphasized the importance of $\mathrm{Na}^{+}$concentration for growth of marine bacteria. He found that the optimum $\mathrm{Na}^{+}$concentration for several marine bacteria was 0.2 to $0.3 \mathrm{M}$, and the results presented here for the cultural studies of $L$. mucor were in agreement with these findings. Although these results indicate that cultural studies may correlate with studies of an organism in its natural environment, it is clear that micro-organisms should be analysed under natural conditions before any conclusions about their activities in the natural environment are made. It should be possible in many cases to carry out these studies through the use of the tritiated thymidine autoradiography technique.

This study was supported by a President's Fellowship of the American Society for Microbiology (to M.T.K.) and a Research Career Development Award from the U.S. Public Health Service (to T.D.B.). The capable assistance of Terri Bruce, Pat Holleman and Sally Murphy is gratefully acknowledged. We thank the Friday Harbor Laboratories, University of Washington (Dr R. Fernald) and the Department of Agriculture and Fisheries for Scotland, Aberdeen (Drs J. Steele and A. L. S. Munro) for providing laboratory facilities for the field research. A portion of this research was supported by a research grant (GB-5758) from the U.S. National Science Foundation. 


\section{REFERENCES}

BROCK, T.D. (1966). The habitat of Leucothrix mucor, a widespread marine organism. Limnol. Oceanogr. II, 303.

Brock, T. D. (1967). Bacterial growth rate in the sea: direct analysis by thymidine autoradiography. Science, N.Y. 155, $8 \mathrm{I}$.

BRock, M. L. \& BROCK, T. D. (1968). The application of micro-autoradiographic techniques to ecological studies. Mitt. Internat. Verein. Limnol. No. I5.

BRock, T.D. \& MANDEL, M. (I966). Deoxyribonucelic acid base composition of geographically diverse strains of Leucothrix mucor. J. Bact. 9r, 1659.

HAIGHT, J. J. \& MoRITA, R. Y. (I966). Some physiological differences in Vibrio marinus grown at environmental and optimal temperatures. Limnol. Oceanogr. xI, 470.

Harold, R. \& StanieR, R. Y. (1955). The genera Leucothrix and Thiothrix. Bact. Rev. r9, 49.

Kelly, M. T. (1969). Physiological ecology and biochemical geography of Leucothrix mucor. Ph.D. Thesis: Indiana University.

Kelly, M. T. \& Brock, T. D. (1969). A warm water strain of Leucothrix mucor. J. Bact. 98, I402.

KORNGOLD, R. R. \& KUSHNER, D. J. (1968). Responses of a psychrophilic marine bacterium to changes in its ionic environment. Can. J. Microbiol. 14, 253.

MACLEOD, R. A. (1965). The question of the existence of specific marine bacteria. Bact. Rev. 29, 9.

OLSEN, R. H. \& METCALF, E. S. (I968). Conversion of mesophilic to psychrophilic bacteria. Science, N.Y. x62, I 288.

SIEBURTH, J. MCN. (1967). Seasonal selection of estuarine bacteria by water temperature. J. exp. mar. Biol. Ecol. x, 98.

Steele, J. H. \& Baird, I. E. (I968). Production ecology of a sandy beach. Limnol. Oceanogr. r3, 14. ZoBeLl, C. E. (1946). Marine Microbiology, p. 241. Waltham, Massachusetts: Chronica Botanica. 